\title{
Long-Lasting Inhibitory Synaptic Depression is Age- and Calcium-Dependent
}

\author{
Vibhakar C. Kotak ${ }^{1}$ and Dan H. Sanes ${ }^{1,2}$ \\ ${ }^{1}$ Center for Neural Science and 2Department of Biology, New York University, New York, New York 10003
}

\begin{abstract}
The developmental refinement of excitatory synapses is often influenced by neuronal activity, and underlying synaptic mechanisms have been suggested. In contrast, few studies have asked whether inhibitory synapses are reorganized during development and whether this is accompanied by use-dependent changes of inhibitory synaptic strength. The topographic inhibitory projection from the medial nucleus of the trapezoid body (MNTB) to the lateral superior olive (LSO) undergoes synapse elimination during development (Sanes and Takács, 1993). To determine whether there is an associated period of synaptic plasticity, whole-cell recordings were obtained from developing LSO neurons of gerbils in a brain slice preparation. In current-clamp recordings, low-frequency stimulation of the MNTB led to a decline in IPSP amplitude by $43 \%$. In voltage-clamp recordings, hyperpolarized
\end{abstract}

LSO neurons also exhibited a long-lasting depression of MNTBevoked inhibitory synaptic currents (34\%) after low-frequency stimulation. When LSO neurons were depolarized, low-frequency stimulation of the MNTB produced a significantly larger inhibitory synaptic depression (59\%). This synaptic plasticity declined dramatically by postnatal days 17-19. Similar to well studied forms of excitatory synaptic plasticity, inhibitory depression depended on postsynaptic calcium. We propose that such activitydependent synaptic depression may support the developmental rearrangement of inhibitory terminals as they compete with neighboring excitatory and/or inhibitory inputs.

Key words: LTD; LSO; inhibition; development; synaptogenesis; calcium
The refinement of excitatory projections has been well described in systems as diverse as the neuromuscular junction and the visual cortex. Furthermore, the formation and elimination of excitatory connections depend, in part, on synaptic transmission. Thus, when neural activity is blocked or altered in the developing visual pathway, excitatory terminals may innervate inappropriate targets (Constantine-Paton et al., 1990; Shatz, 1990). The mechanism that mediates excitatory synaptic refinement is not yet known, although there is strong evidence that NMDA receptors are involved in the activity-dependent stabilization of glutamatergic connections in the CNS (Constantine-Paton and Cline, 1998). At the vertebrate neuromuscular junction, excitatory synapse elimination may rely on a calcium-dependent depression mechanism (Lo and Poo, 1994; Cash et al., 1996; Colman et al., 1997). Despite these tremendous advances in our understanding of excitatory synaptic plasticity in developing systems, there is little information about the activitydependent refinement of central inhibitory connections. In the present study, we demonstrate use-dependent depression at a set of inhibitory synapses that are known to be refined via a process of synapse elimination (Sanes and Takács, 1993).

One reason that motor neuron and retinal ganglion cell afferents have been so well studied is that they form pure excitatory projections. To test selectively the role of inhibitory transmission during development, it seemed important to identify a similar kind of projection. The lateral superior olivary nucleus (LSO) is a central auditory structure that encodes interaural level differences, an acoustic cue that is used for sound localization. LSO neurons perform this computation by integrating excitatory inputs driven by the ipsilateral ear with inhibitory inputs driven by the contralateral ear (see Fig. $1 A$ ). Inhibitory afferents from the medial nucleus of the trapezoid body (MNTB) form a tonotopic projection in LSO that is aligned with the ipsilateral excitatory projection (Sanes and Rubel, 1988). During postnatal development, individual MNTB arbors become $\sim 30 \%$ more restricted along the frequency axis

\footnotetext{
Received Jan. 18, 2000; revised April 19, 2000; accepted May 10, 2000.

This work was supported by National Institutes of Health Grant DC 00540 (D.H.S.)

Correspondence should be addressed to Dr. Dan H. Sanes, Center for Neural Science, 4 Washington Place, New York University, New York, NY 10003. E-mail: sanes@cns.nyu.edu.

Copyright (C) 2000 Society for Neuroscience $0270-6474 / 00 / 205820-07 \$ 15.00 / 0$
}

(Sanes and Siverls, 1991). Furthermore, if MNTB neurons are functionally denervated by removal of the contralateral ear, then the arbors remain in their expanded state, suggesting the involvement of an activity-dependent mechanism (Sanes and Takács, 1993). Recently, it has been found that inhibitory terminals on another binaural nucleus, called the medial superior olivary nucleus (MSO), also undergo a period of synaptic pruning (Kapfer et al., 1999). In this case, inhibitory synapses are initially spread out along MSO dendrites but are restricted to the soma during development, a process that also appears to require activity. Taken together, these data suggest that MNTB synapses may compete with inhibitory and/or excitatory terminals for postsynaptic space during early postnatal development. Therefore, we asked whether inhibitory afferent activity influences the strength of their inhibitory synapses within the LSO. Specifically, we were interested in exploring whether activation of MNTB afferents at low levels could decrease inhibitory transmission in the LSO, because lowfrequency stimulation of excitatory afferents has been shown to produce a decline in excitatory synaptic strength (Dudek and Bear, 1992).

\section{MATERIALS AND METHODS}

MNTB-LSO slice preparation. Gerbils (Meriones unguiculatus) aged postnatal day 7 (P7)-P12 or P17-P19 were used to generate $300 \mu \mathrm{m}$ transverse brain slices through the LSO and medial nucleus of the trapezoid body (Sanes, 1993). The artificial CSF (ACSF) contained (in mM): $125 \mathrm{NaCl}, 4$ $\mathrm{KCl}, 1.2 \mathrm{KH}_{2} \mathrm{PO}_{4}, 1.3 \mathrm{MgSO}_{4}, 26 \mathrm{NaHCO}_{3}, 15$ glucose, $2.4 \mathrm{CaCl}_{2}$, and 0.4 $\mathrm{L}$-ascorbic acid, $\mathrm{pH}=7.3$ when bubbled with $95 \% \mathrm{O}_{2} / 5 \% \mathrm{CO}_{2}$. ACSF was continuously superfused in the recording chamber at $5 \mathrm{ml} / \mathrm{min}$ at room temperature $\left(23-24^{\circ} \mathrm{C}\right)$.

Whole-cell electrophysiology and pharmacological manipulations. Initially, whole-cell current-clamp recordings were performed in LSO to examine the influence of prolonged MNTB stimulation (see Fig. $1 B ; n=10$ ). Recording electrodes were fabricated from borosilicate glass microcapillaries $(1.5 \mathrm{~mm}$ outer diameter), and their resistance ranged from 5 to 10 $\mathrm{M} \Omega$. Access resistance was balanced throughout the recordings and generally ranged between 15 and $40 \mathrm{M} \Omega$. The internal patch solution contained (in mM): 127.5 potassium gluconate, 0.6 EGTA, 10 HEPES, 2 $\mathrm{MgCl}_{2}, 5 \mathrm{KCl}, 2 \mathrm{ATP}$, and $0.3 \mathrm{GTP}, \mathrm{pH}=7.2$

In the majority of experiments, whole-cell voltage-clamp recordings were obtained from LSO neurons at a holding potential of -55 to $-90 \mathrm{mV}$ (see Fig. 2; $n=10$ ) or $0 \mathrm{mV}$ (see Fig. 3; $n=21$ ), while electrical stimuli were delivered directly to the MNTB (see Fig. $1 A$ ). The wide range of hyperpolarizing holding potentials was chosen to record IPSCs at an 
operational resting potential level or, if the ISPCs were small, at more hyperpolarized levels to increase the driving force and thus enhance their baseline amplitude. The internal patch solution contained cesium gluconate $(127.5 \mathrm{~mm})$ to block most potassium channels, and QX-314 $(5 \mathrm{~mm})$ was added to block voltage-dependent sodium channels. The rest of the constituents (in $\mathrm{mM}$ ) were the same as those in current clamp ( $\mathrm{pH}=7.2)$. To decrease postsynaptic free calcium, BAPTA $(20 \mathrm{~mm})$ was added to the recording pipette solution in some experiments. This solution was made separately, and the $\mathrm{pH}$ was adjusted to 7.2. A Warner Instruments PC501A was used for recordings, and $\sim 70 \%$ of the access resistance was compensated.

After a whole-cell voltage-clamp recording was obtained (Kotak et al., 1998), a modified ACSF with kynurenic acid (5 mM; pH adjusted to 7.3) was superfused for $6 \mathrm{~min}$ before adjusting the holding potential either to -55 to $-90 \mathrm{mV}$ or to $0 \mathrm{mV}$ for the duration of the recording. Under these conditions, MNTB-evoked maximum IPSCs were recorded as inward or outward currents, respectively (Kotak et al., 1998). The voltage pulse (200 $\mu \mathrm{sec})$ that evoked the maximum amplitude IPSC was used for the remainder of the experiment. During a 15 min control period, MNTB-evoked IPSCs were acquired every minute for the first $5 \mathrm{~min}$ and then at 10 and 15 min. MNTB was then activated with low-frequency stimulation (LFS; $1 \mathrm{~Hz}$ for $15 \mathrm{~min}$ ). This protocol was chosen because it has been shown previously to induce long-term depression (LTD) of excitatory synapses in the hippocampus (Dudek and Bear, 1992). In addition to hyperpolarized potentials, a holding potential of $0 \mathrm{mV}$ was selected because a similar pairing of depolarization and $1 \mathrm{~Hz}$ stimulation was used to study agedependent plasticity of excitatory connections in barrel cortex (Crair and Malenka, 1995) and robust IPSCs free of EPSCs were recorded previously (Kotak et al., 1998). A small number of P7-P12 neurons $(n=6)$ exhibited a significant and rapid reduction of MNTB-evoked IPSCs during the initial $15 \mathrm{~min}$ control period, and these neurons were excluded from the analysis because we believed this behavior indicated a sudden decline in viability.

Immediately after LFS, MNTB-evoked IPSCs were recorded every minute for the first $5 \mathrm{~min}$ and then every $5 \mathrm{~min}$ for the next hour. The total duration of the experiments was therefore typically $90 \mathrm{~min}$. In some cases, recording was extended for an additional hour. The IPSC amplitudes and their slopes were analyzed off-line using custom software (Sanes, 1993). In some neurons, to see the effect of the absence of LFS and the interim afferent activity during the $90 \mathrm{~min}$ data acquisition, five IPSCs were recorded before and $90 \mathrm{~min}$ after holding the cells at $\mathrm{V}_{\mathrm{HOLD}}=-80 \mathrm{mV}$ $(n=6)$ or $\mathrm{V}_{\mathrm{HOD}}=0 \mathrm{mV}$.

To assess the effect of a potent $\left[\mathrm{Ca}^{2+}\right]_{\mathrm{i}}$ chelator, a separate group of recordings were performed with $20 \mathrm{~mm}$ BAPTA (Molecular Probes, Eugene, OR) in the internal recording solution at $\mathrm{V}_{\mathrm{HOLD}} \leq-55 \mathrm{mV}(n=7)$ or $\mathrm{V}_{\mathrm{HOLD}}=0 \mathrm{mV}(n=12)$.

\section{RESULTS}

Current-clamp recordings were obtained from LSO neurons without any pharmacological manipulations, while electrical stimuli were delivered directly to the MNTB (Fig. $1 A)$. LFS $(1 \mathrm{~Hz}$ for 15 min) of the MNTB produced long-lasting depression of the evoked IPSPs. At 60 min after LFS, the IPSP amplitude declined by $43 \pm$ $7 \%(n=10$; mean \pm SEM $)$ when compared with the initial IPSP amplitude (Fig. 1B). The membrane potential of some neurons changed by up to $6 \mathrm{mV}$ after LFS. Therefore, to determine whether depolarization itself could generate a similar IPSP reduction, we raised membrane potential by $10-15 \mathrm{mV}(n=5)$. Before LFS, the IPSP amplitude increased by $3.2 \pm 0.3 \mathrm{mV}$ during membrane depolarization. After LFS, the increase in IPSP amplitude was $1.1 \pm 0.3 \mathrm{mV}$ (mean $\pm \mathrm{SEM}$ ). Thus, in both control and depressed conditions, the increased IPSP amplitude during membrane depolarization was approximately proportional to the IPSP amplitude at rest.

To better assess long-lasting depression of MNTB-evoked inhibitory transmission, we performed the remainder of the experiments under voltage-clamp conditions, while ionotropic glutamate receptors were blocked pharmacologically. At a holding potential of -55 to $-90 \mathrm{mV}$, when MNTB was directly stimulated, IPSCs were recorded as inward currents (Fig. $2 A$ ). At these hyperpolarized potentials, LFS ( $1 \mathrm{~Hz}$ for $15 \mathrm{~min}$ ) of the MNTB produced longlasting depression of the evoked IPSCs (Fig. 2B). At 60 min after LFS, the IPSC amplitude declined by $34 \%$ when compared with the initial IPSC amplitude (Fig. 2B). To determine whether synaptic depression was caused by the LFS and in absence of any afferent activation, recordings were obtained for an equivalent amount of time $(90 \mathrm{~min})$ without any stimulation of the MNTB (Fig. 2B, asterisks). The LFS treatment induced a significant depression when compared with these control recordings.

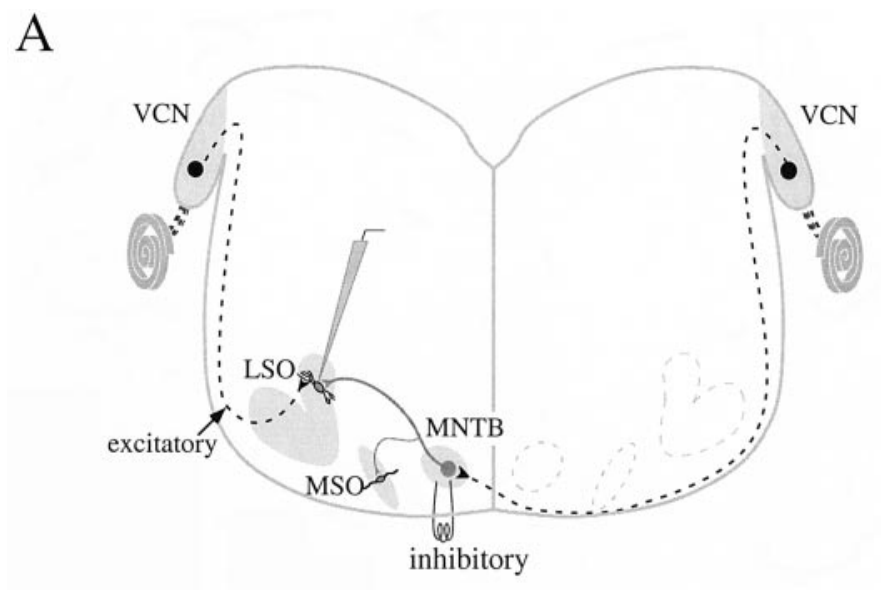

\section{B Current Clamp}

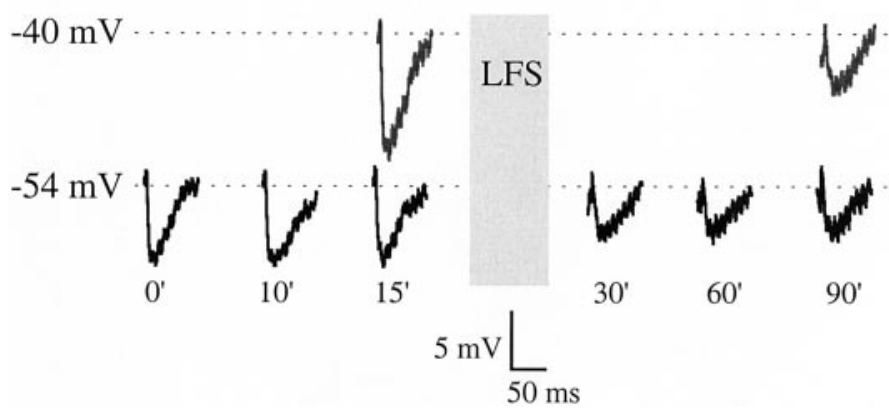

Figure 1. Long-lasting depression of inhibitory synapses in the LSO. A, Schematic of the inhibitory pathway from MNTB to LSO used in the present study is shown. LSO neurons receive a direct inhibitory projection from several MNTB neurons and excitatory inputs from several ipsilateral ventral cochlear nucleus $(V C N)$ neurons. MNTB neurons also project to the MSO. $B$, IPSPs were recorded from the medial limb of the LSO, while electrical stimuli were delivered to the MNTB. In this P9 LSO neuron, IPSP amplitude remained fairly stable during the first $15 \mathrm{~min}$ recording period (the time at which each IPSP was obtained is shown beneath each trace). LFS ( $1 \mathrm{~Hz}$ for $15 \mathrm{~min}$; gray bar) was then provided to the MNTB at a stimulus intensity that evoked a maximum amplitude IPSP. IPSPs were depressed during the $1 \mathrm{hr}$ period after LFS. The bottom dashed line indicates the initial resting membrane potential. During the pre-LFS period, the amplitude of an IPSP recorded at a $-40 \mathrm{mV}$ membrane potential $(+0.02 \mathrm{nA})$ was augmented by $\sim 3 \mathrm{mV}$, and a similar depolarization $1 \mathrm{hr}$ after LFS increased the depressed IPSP by $\sim 1 \mathrm{mV}$.

In a separate set of recordings, we determined whether inhibitory synaptic depression was influenced by postsynaptic membrane potential. LSO neurons were held at $0 \mathrm{mV}$, and electrical stimuli were once again delivered to the MNTB while IPSCs were recorded as outward currents. As shown for one P9 neuron in Figure $3 A$, MNTB-evoked IPSCs were $\sim 110 \mathrm{pA}$ during the first $15 \mathrm{~min}$ of recording but decreased to $\sim 50 \mathrm{pA}$ after LFS. All 21 neurons recorded from $\mathrm{P} 7$ to $\mathrm{P} 12$ slices displayed a depression whose magnitude was significantly greater than that recorded at hyperpolarized potentials (see Fig. 6). As shown in Figure $3 B$, the IPSC amplitude decreased by over 55\% at 50-60 min after LFS. There was also a complementary decline in IPSC slope (before LFS, $7.4 \pm 0.7 \mathrm{pA} / \mathrm{msec}$; after LFS, $3.5 \pm 0.4 \mathrm{pA} / \mathrm{msec}$ ), indicating that the peak IPSC amplitude and its time to peak had both decreased concomitantly. In five neurons, the recording continued for $2 \mathrm{hr}$ after LFS, and the synaptic depression persisted during this period. When recordings were obtained for $90 \mathrm{~min}$ in the absence of LFS to the MNTB (but with continued acquisition of IPSCs), a $21 \%$ decrease in IPSC amplitude was observed (Fig. 3B). In addition, there was a small $(\sim 15 \%)$, but significant, decline in IPSC amplitude in the absence of any interim MNTB activity (see Figs. $3 B, 6$ ). The IPSC amplitude in LFS-treated neurons was significantly 
A

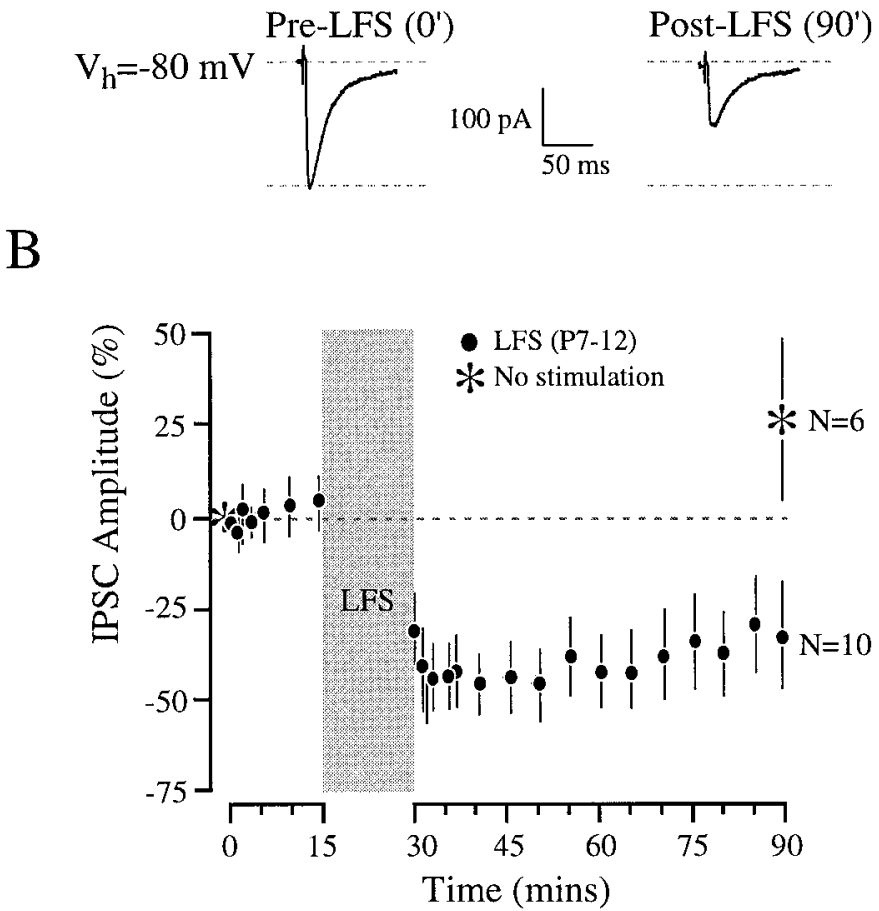

Figure 2. Long-lasting depression of inhibitory synapses in the LSO at a holding potential of $-55 \mathrm{mV}$ or less (voltage clamp). $A$, Representative recordings from a P10 LSO neuron show a maximum amplitude IPSC recorded at $\mathrm{V}_{\mathrm{HOLD}}=-80 \mathrm{mV}$ at the beginning of the experiment $(0 \mathrm{~min})$ and its post-LFS depression at the end of the experiment $(90 \mathrm{~min}) . B$, Long-lasting depression of IPSCs for all recorded LSO neurons at P7-P12 is shown. Means ( \pm SEM) of IPSCs show that synaptic depression was significant after LFS (black circles). Age-matched control neurons that did not receive any LFS or intermediary MNTB stimulation (asterisks) did not get depressed. See Figure 6 for statistics.

reduced compared with both control groups (see Fig. 6). The effect was not caused by the particular glutamatergic antagonist used (kynurenic acid) because depression was also observed in the presence of $20 \mu \mathrm{M}$ CNQX and $40 \mu \mathrm{M}$ AP-5 (62\% depression at 60 min after LFS; $n=2$ ).

If inhibitory synaptic depression is a developmental mechanism that is specifically involved in the refinement of inhibitory MNTB synapses, then we might expect to see a decline in plasticity after anatomical refinement has been primarily completed (Sanes and Siverls, 1991). Therefore LSO neurons were recorded at $\mathrm{V}_{\mathrm{HOLD}}=$ $0 \mathrm{mV}$ in P17-P19 slices to test the age dependence of synaptic depression. As shown in Figure 4, although LFS produced a decline in IPSC amplitude at P17-P19, this decrease was significantly less when compared with the depression in IPSCs in the P7-P12 group otherwise treated under similar conditions (see Fig. 6).

We next asked whether postsynaptic calcium was necessary to elicit inhibitory synaptic depression. A calcium chelator (BAPTA, $20 \mathrm{~mm}$ ) was added to the pipette solution and allowed to equilibrate for $5 \mathrm{~min}$ before the experiment commenced. We performed the BAPTA manipulation experiments at both hyperpolarized and depolarized holding potentials because depression was recorded in either condition. As shown in Figures 5 and 6, this manipulation completely eliminated inhibitory synaptic depression after LFS in P7-P12 neurons. In fact, we observed potentiation of MNTBevoked IPSCs after LFS in 6 of the 12 neurons recorded at $\mathrm{V}_{\text {HOLD }}=0 \mathrm{mV}$.

Finally, we considered the possibility that two factors could contribute to synaptic depression: a general change in the postsynaptic excitability or a depolarizing shift in $E_{\text {IPSC }}$. Alteration of postsynaptic membrane properties could not have produced the

\section{$\underline{\text { Voltage Clamp }}$}

A
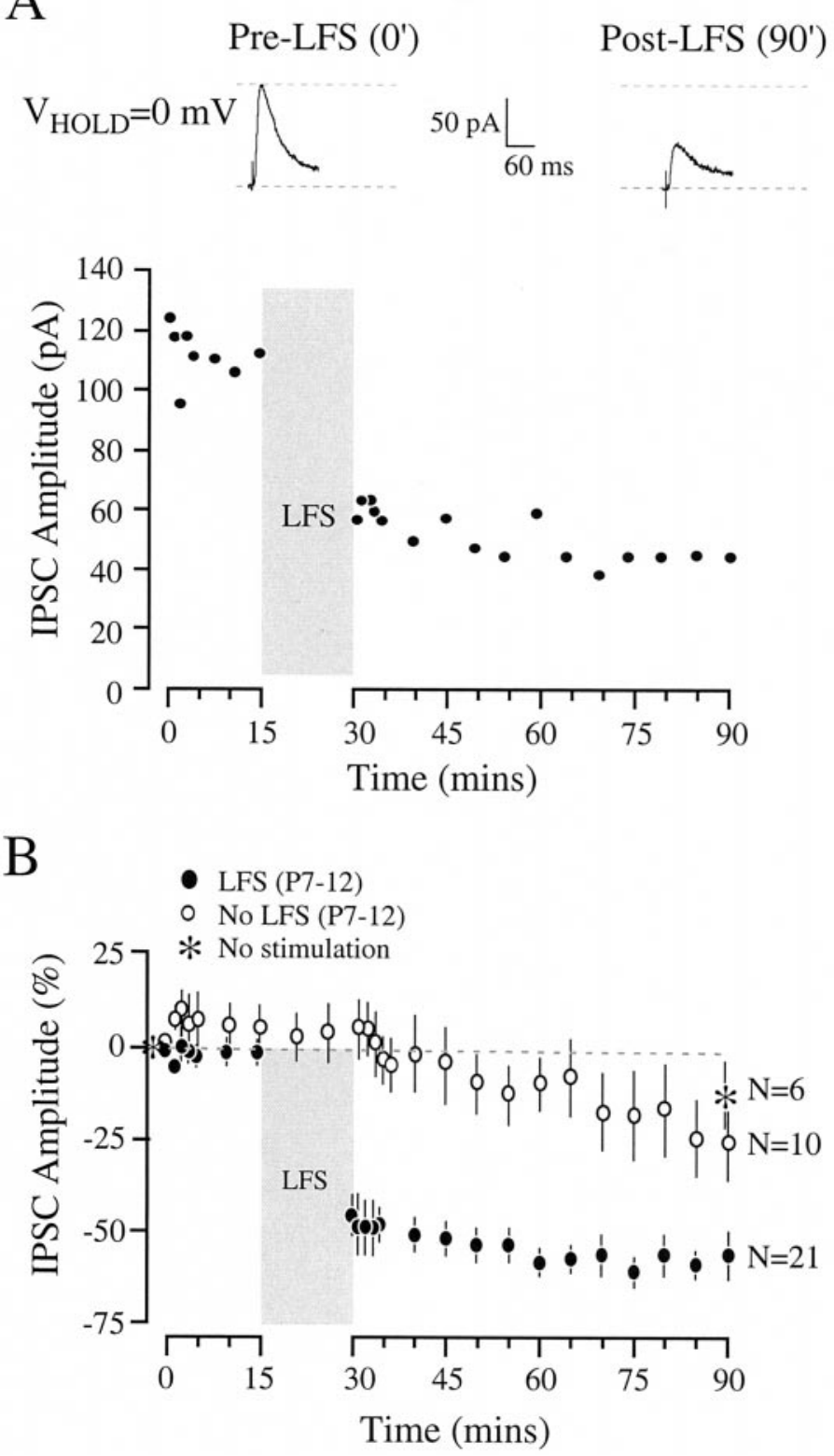

Figure 3. Long-lasting depression of inhibitory synapses in the LSO at a holding potential of $0 \mathrm{mV}$. A, Long-lasting depression of inhibitory transmission for an individual P9 LSO neuron is shown. Top, Representative MNTB-evoked IPSCs are shown before (left) and after (right) LFS. Bottom, The amplitude of IPSCs in one neuron declined dramatically after LFS, and this depression persisted for $1 \mathrm{hr}$. B, Long-lasting depression of IPSCs for all recorded LSO neurons at P7-P12 is shown. Means ( \pm SEM) of IPSCs show that synaptic depression was profound after LFS (black circles). Age-matched control neurons in which LFS was not delivered (white circles) or without LFS and intermediary MNTB stimulation (asterisks) displayed a smaller, but significant, decrease in amplitude.

depression because the minor change in holding current $\left(I_{\mathrm{HOLD}}\right)$ during the period of recording was nearly identical for both LFStreated and control neurons. In fact, the $I_{\mathrm{HOLD}}$ decrease was slightly greater for control neurons (control, $-48 \pm 10 \mathrm{pA}$; LFS, $-35 \pm 7 \mathrm{pA} ; t=1.019 ; p=0.32$ ). Nonetheless, to determine whether $I_{\mathrm{HOLD}}$ contributed to depression, IPSCs were reanalyzed after the holding current was adjusted to its pre-LFS value. This manipulation did not change IPSC amplitude significantly (before LFS, $128 \pm 10 \mathrm{pA}$; after LFS, $56 \pm 8 \mathrm{pA}$; after LFS with adjustment of $\left.I_{\mathrm{HOLD}}, 74 \mathrm{pA} \pm 11 \mathrm{pA} ;=2.0 ; p=0.16 ; n=9\right)$. The 


\section{Voltage Clamp}
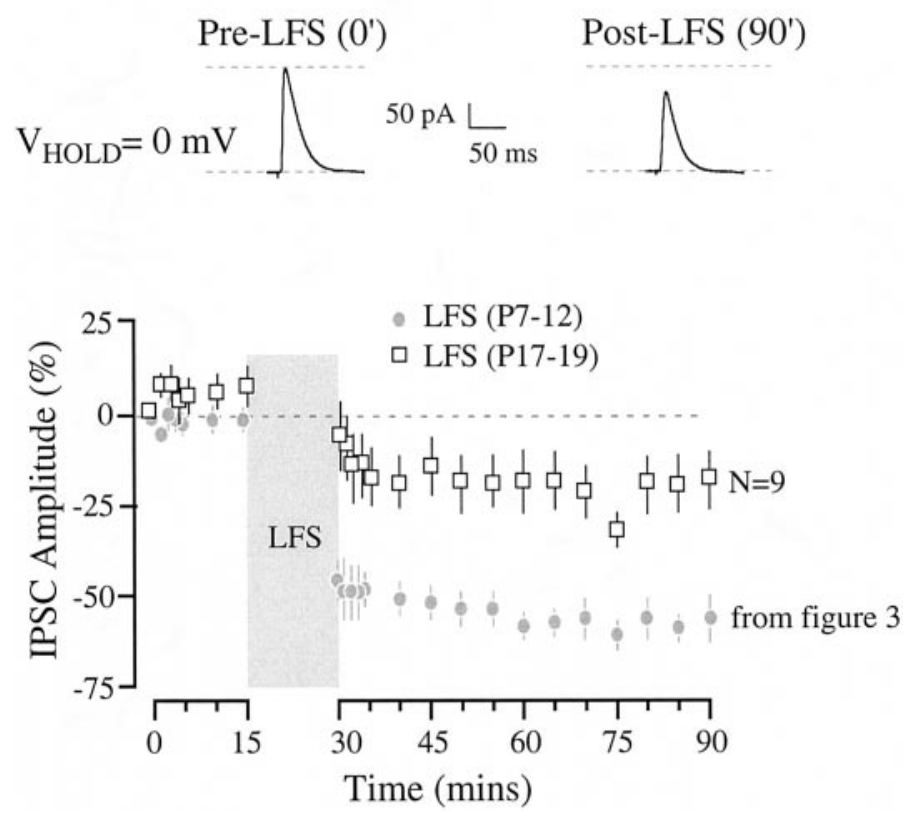

Figure 4. Long-lasting synaptic depression was age-dependent. Top, MNTB-evoked IPSCs in a P17 neuron before LFS (left) and 60 min after LFS (right). Bottom, A comparison of summary data from P17 to P19 LSO neurons that were treated with LFS (white squares) with data from P7 to P12 neurons (gray circles). The magnitude of synaptic depression in the older age group is much reduced (see Fig. 6 for statistics).

$E_{\text {IPSC }}$ also depolarized slightly during the course of the experiments (before LFS, $E_{\mathrm{IPSC}}=-40 \pm 1.5 \mathrm{mV}$; after LFS, $E_{\mathrm{IPSC}}=$ $-33 \pm 2.6 \mathrm{mV} ; t=2.0 ; p=0.02 ; n=11)$. However, we found that there was a significant decline in the inhibitory conductance after LFS, suggesting that the driving force $\left(E_{\mathrm{HOLD}}-E_{\mathrm{IPSC}}\right)$ played only a minor role in depression (before LFS, $4.7 \pm 0.8 \mathrm{pS}$; after LFS, $2.3 \pm 0.2 \mathrm{pS} ; t=2.08 ; p=0.05 ; n=11$ ). In fact, inhibitory depression of $>50 \%$ was observed in three LSO neurons without any shift in $E_{\text {IPSC }}$.

\section{DISCUSSION}

Our study attempts to bridge previous data showing that inhibitory synapses are rearranged in the developing central auditory system (Sanes and Takács, 1993) with a candidate mechanism, long-lasting depression of synaptic transmission. There are several lines of evidences that synaptic depression contributes to the developmental reduction of polyneuronal innervation at the nerve-muscle junction. Electrical stimulation of one set of motor axons can speed up the process of synapse elimination and produce a weakening of unstimulated terminals (O'Brien et al., 1978; Ridge and Betz, 1984; Balice-Gordon and Lichtman, 1994; Lo and Poo, 1994). This mechanism appears to be dependent on a postsynaptic rise in calcium (Connold et al., 1986; Cash et al., 1996). LTD of excitatory synapses is also well characterized in the CNS (Linden and Connor, 1995), and an age-dependent decline of excitatory LTD has been demonstrated (Battistin and Cherubini, 1994; Dudek and Friedlander, 1996; Feldman et al., 1998). For example excitatory LTD is present in layer IV of the visual cortex in juvenile cats and guinea pigs but is virtually absent in adult animals (Dudek and Friedlander, 1996).

In the LSO, several experimental findings suggest that spontaneous inhibitory activity influences the maturation of neuronal morphology and physiology within the LSO, including the expression of NMDA receptors (Sanes et al., 1992; Kotak and Sanes, 1996; Sanes and Hafidi, 1996). The present results are broadly consistent with the remodeling of inhibitory synaptic pathways during development (Sanes and Siverls, 1991; Sanes and Takács, 1993). Inhibitory depression recorded under either current- (Fig. 1) or voltage-clamp (Figs. 2-6) conditions, and at different holding potentials, supports the hypothesis that this phenomenon may be an integral element of inhibitory synaptogenesis. In other forms of inhibitory plasticity that decrease GABAergic transmission, glutamate may mediate depolarization-induced suppression of inhibition via a metabotropic signaling at the interneuron-Purkinje cell synapse (Glitsch et al., 1996) or at the hippocampal CA1 neurons (Morishita et al., 1998). In our experiments, inhibitory depression was maximized by a postsynaptic depolarization and high intracellular calcium.

Inhibitory synaptic depression was strongest in P7-P12 LSO neurons (Figs. 1-3), near the onset of response to airborne sound (Finck et al., 1972; Harris and Dallos, 1984; Woolf and Ryan, 1985; Sanes and Siverls, 1991). By P17-P19, the magnitude of inhibitory depression had declined to less than one-half the magnitude observed in younger animals (Fig. 4). Thus, the age at which inhibitory depression was observed correlates rather precisely with the period of normal inhibitory synapse elimination (Sanes and Siverls, 1991). If use-dependent synaptic depression is to have an effect on inhibitory synaptogenesis, then it is important to determine whether neural activity exists during the period of inhibitory synapse elimination. We have shown previously that spontaneous activity is present in the developing gerbil auditory nervous system, but at a relatively low level (Kotak and Sanes, 1995). In vivo recordings confirm that inhibitory synaptic drive is present by postnatal day 13 (Sanes and Rubel, 1988). In addition, the rate of spontaneous inhibitory synaptic currents can be dramatically enhanced by serotonin (Fitzgerald and Sanes, 1999). Thus, inhibitory depression could be elicited by either spontaneous or driven inhibitory synaptic activity in vivo.

Inhibitory synaptic depression occurred after a relatively brief (1 $\mathrm{Hz} ; 15 \mathrm{~min}$ ) train of stimuli to the entire MNTB afferent population. As shown in Figure 2, the effect was observed when LSO neurons were held at a potential equal to, or more hyperpolarized than, their normal resting membrane potential (less than or equal to $-55 \mathrm{mV}$ ). The depression was clearly related to synapse activity in that nonstimulated preparations displayed no depression after 90 min of recording (Fig. 2). Therefore, it is possible the inhibitory synapses compete with one another on the basis of their ability to evoke a postsynaptic response. When LSO neurons were depolarized to $0 \mathrm{mV}$, LFS produced a significantly greater depression of the evoked IPSCs (Fig. 3). This result suggests that excitatory synaptic activity may actually facilitate the inhibitory depression mechanism.

Intracellular free calcium was a necessary component of inhibitory synaptic depression, evoked at either hyperpolarized or depolarized membrane potentials (Fig. 5). Addition of the calciumchelating agent BAPTA to the pipette solution resulted in the complete absence of depression after LFS. In fact, there was some indication that very low postsynaptic calcium levels were associated with a potentiation of the evoked IPSC. A $20 \%$ increase in the IPSC amplitude was observed at 90 min when LFS was delivered in the presence of intracellular BAPTA (Fig. 5).

Although calcium was involved in synaptic depression at 0 or less than or equal to $-55 \mathrm{mV}$, it is likely that the mechanism of calcium entry or mobilization differs under these two conditions. For example, neonatal inhibitory synapses have been shown to evoke depolarizing postsynaptic potentials because the chloride extrusion mechanism is not yet mature (Payne et al., 1996; Plotkin et al., 1997; Backus et al., 1998; Ehrlich et al., 1999; Kakazu et al., 1999; Lu et al., 1999; Rivera et al., 1999; Williams et al., 1999). Depolarizing IPSPs only are observed until approximately P7 in the rat LSO (Kandler and Friauf, 1995). In this study, persistent activation of inhibitory synapses does not lead to an inversion of the chloride gradient because IPSPs remained hyperpolarizing even after LFS (Fig. 1). A direct increase of postsynaptic calcium by inhibitory activity (Connor et al., 1987; Ben-Ari et al., 1989; Ito and Cherubini, 1991; Obrietan and Van den Pol, 1995; Boehm et al., 1997; Lo 

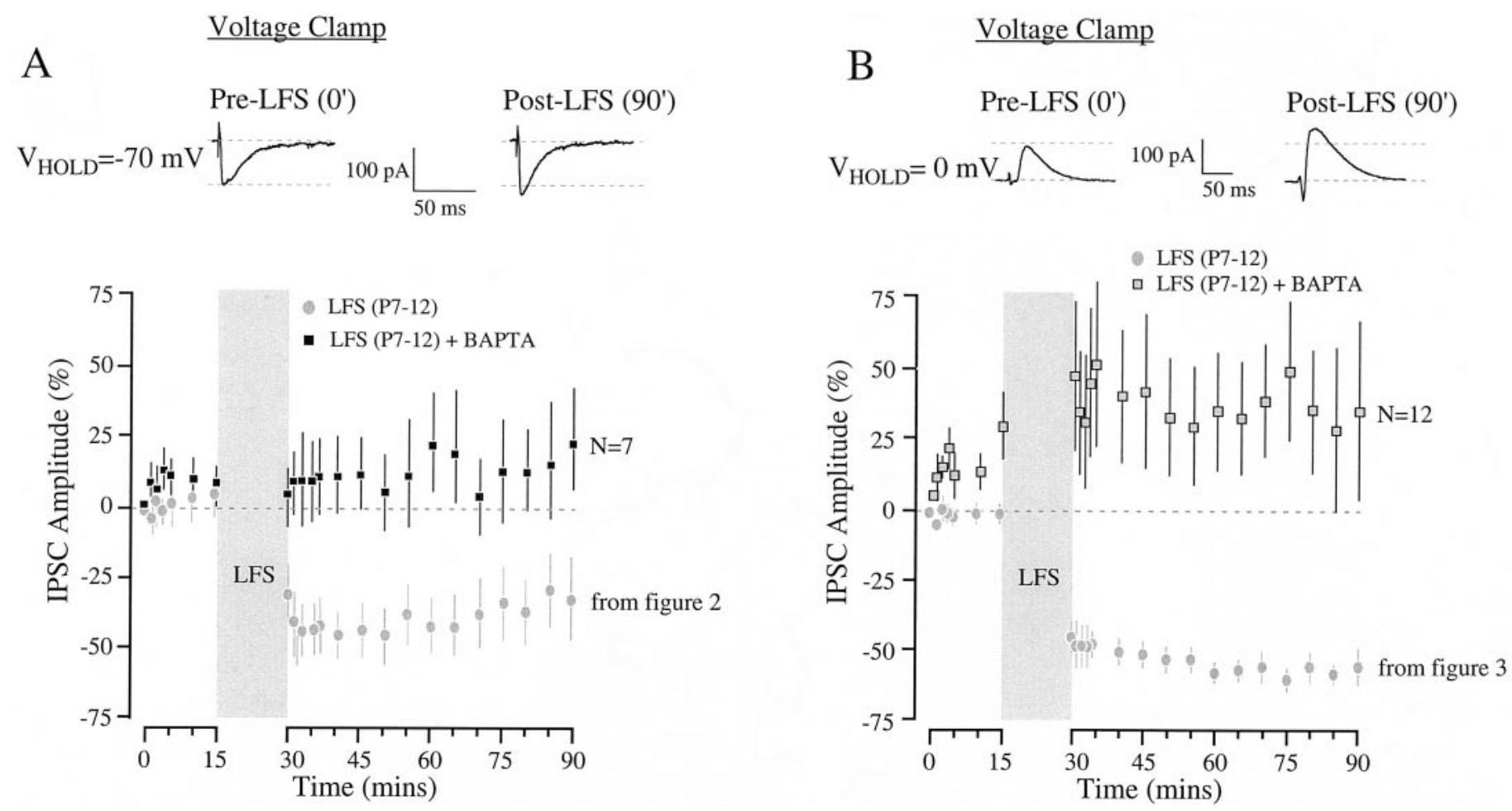

Figure 5. Long-lasting synaptic depression was calcium-dependent. A, Bottom, Comparison of synaptic depression in P7-P12 neurons at holding potentials of less than or equal to $-55 \mathrm{mV}$ recorded with normal pipette solution [gray circles (from Fig. 2)] or with pipette solution containing 20 mM BAPTA (black squares). Synaptic depression was abolished by intracellular perfusion with BAPTA (see Fig. 6 for statistical comparisons). Top, Representative current traces for one BAPTA-treated P9 neuron. B, Bottom, Comparison of synaptic depression in P7-P12 neurons at a holding potential of $0 \mathrm{mV}$ recorded with normal pipette solution [gray circles (from Fig. 3)] or with pipette solution containing 20 mM BAPTA (gray squares). Synaptic depression was abolished by intracellular perfusion with BAPTA (see Fig. 6 for statistical comparisons). Top, Representative current traces for one BAPTA-treated P9 neuron. Note that the mean size of IPSCs in BAPTA-treated neurons became larger after LFS, although the variance was high.

Figure 6. Comparison of percent change of IPSC amplitude at $90 \mathrm{~min}$ in each experimental group. At $\mathrm{V}_{\mathrm{HOLD}} \leq-55 \mathrm{mV}$, LFS produced a significant change in IPSC amplitude as compared with no stimulation (No Stim; $p<0.05$; $t=$ symbol 452.16 ; $\mathrm{df}=14$ ) or LFS + BAPTA $(p<0.05 ; t=2.1 ; \mathrm{df}=15)$. At $\mathrm{V}_{\mathrm{HOLD}}=0 \mathrm{mV}$, LFS at P7-P12 produced a significant change in IPSC amplitude as compared with no LFS ( $p<$ $0.0005 ; t=$ symbol 453.6 ; $\mathrm{df}=29)$, no stimulation $(p<0.05 ; t=$ symbol $453.6 ; \mathrm{df}=29)$, LFS at P17-P19 $(p<0.0005 ; t=$ symbol 45 4.14 ; df $=28)$, or LFS + BAPTA $(p<0.0001$; $t=3.6 ; \mathrm{df}=31$ ). Finally, LFS induced a significantly greater reduction in IPSC amplitude when delivered at $\mathrm{V}_{\mathrm{HOLD}}=0$ as compared with $\mathrm{V}_{\mathrm{HOLD}} \leq-55(p<0.05 ; t=2.23 ; \mathrm{df}=29)$. The mean percent change was calculated by comparing the average IPSC amplitude recorded at 50-60 min after LFS with the initial IPSC amplitude.

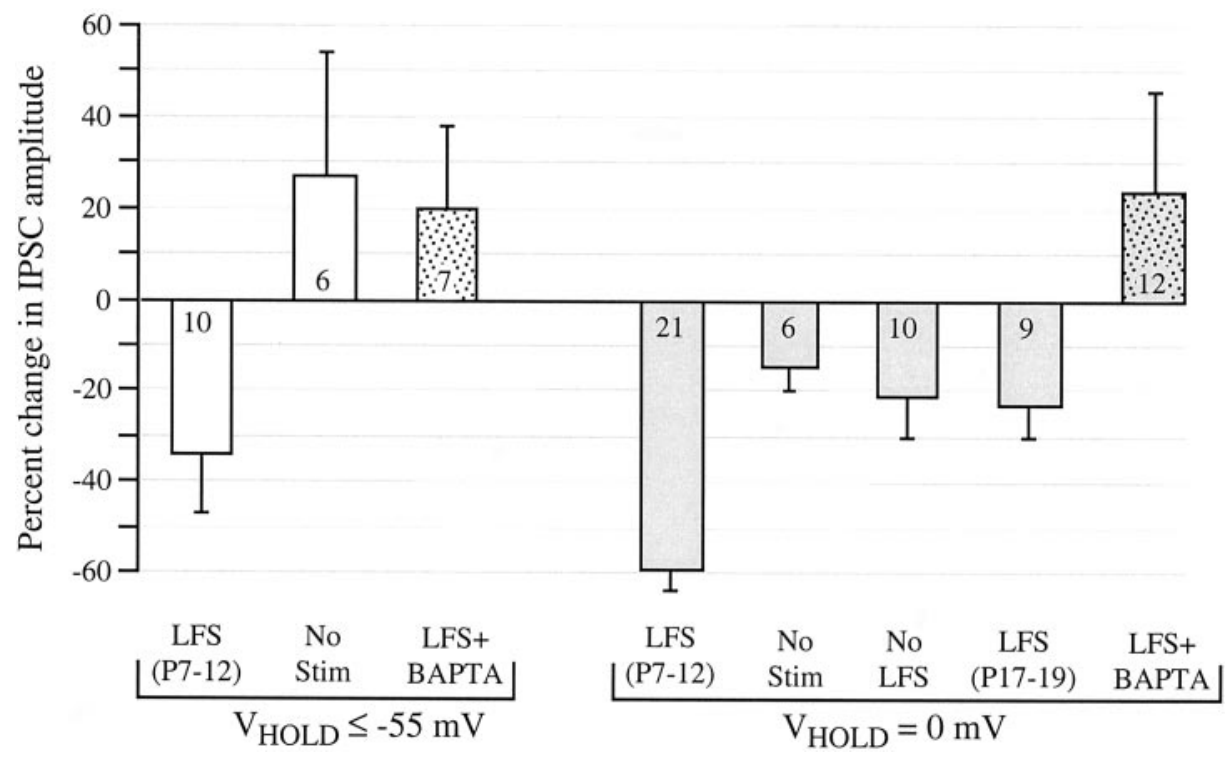

et al., 1998; Kullman and Kandler, 1999) after P8 in the gerbil LSO thus appears an unlikely mechanism for calcium-mediated depression, although the blockade of depression by BAPTA suggests that intracellular free calcium is a necessary element (Fig. 5).

Although the inefficient space clamp of distal LSO neuron dendrites during hyperpolarizing holding potential commands at the soma must be kept in mind, it is difficult to explain how the LSO calcium concentration could be increased when the membrane potential is held at a hyperpolarized level. One other possibility is that the inhibitory synapses activate a metabotropic pathway. For example, we have reported previously that inhibitory synapses are predominantly GABAergic at P3-P5 and become primarily glycinergic by P16 (Kotak et al., 1998). Furthermore, functional $\mathrm{GABA}_{\mathrm{B}}$ receptors are present during the ages when GABA is released. It is also known that MNTB neurons contain $\mathrm{BDNF}$ and that LSO neurons express the cognate receptor TrkB during development (Hafidi et al., 1996; Hafidi, 1999). Although we have no firm candidate at this time, it seems plausible that inhibitory synapses may do more than simply open ligand-gated chloride channels.

Modulation of inhibitory synaptic strength has been reported in several systems. For example, there is short-term facilitation or 
depression of IPSPs in P20-P40 auditory cortex (Buonomano and Merzenich, 1998) and inhibitory long-term potentiation (LTP) and LTD in the hippocampus (Morishita and Sastry, 1991). In goldfish, inhibitory inputs show LTP (Oda et al., 1995, 1998). Although there are a few accounts of inhibitory synaptic plasticity in the developing nervous system (Komatsu, 1994), these are not known to be associated with a developmental rearrangement of inhibitory terminals. Furthermore, it is not clear how the timing of excitatory and inhibitory events might influence the strength of either afferent projection. The relative timing of excitatory synaptic events can influence whether excitatory LTD or LTP is observed. In the Xenopus retinotectal system, an EPSC that occurs $\sim 20 \mathrm{msec}$ before a postsynaptic action potential is potentiated, whereas an EPSC that occurs $\sim 20 \mathrm{msec}$ after the action potential is depressed (Zhang et al., 1998).

We therefore propose that inhibitory terminals become stabilized when they are active during low postsynaptic calcium. Low intracellular calcium levels could exist because of the lack of excitatory activity, because of the ability of inhibitory terminals to hyperpolarize the membrane potential during brief activation (Callaway et al., 1995; Lo et al., 1998), or in much older animals $(>$ P20) because their intracellular calcium-buffering efficacy could be greater (Friauf, 1994; Lohmann and Friauf, 1996; Parks et al., 1996; Zettel et al., 1997; Caicedo et al., 1998; Henkel and BrunsoBechtold, 1998; Iwasaki and Takahashi, 1998). If excitatory terminals are activated first, the subsequent transmission at inhibitory terminals may lead to inhibitory synapse withdrawal. Although the MNTB-evoked IPSC became depressed, we do not yet know whether this represents the selective depression of some inhibitory synapses or the widespread depression of them all.

From a functional standpoint, one of the most intriguing elements of LSO development is the manner in which excitatory and inhibitory afferents become precisely matched, both structurally and functionally, along the tonotopic axis (Sanes and Rubel, 1988; Sanes and Siverls, 1991). Individual MNTB arbors become $\sim 30 \%$ more restricted along the LSO frequency axis during the third postnatal week (Sanes and Siverls, 1991). On the basis of estimates from intracellular recordings, the refinement of MNTB arbors correlates with the loss of $\sim 40 \%$ of the inhibitory inputs to each LSO neuron (Sanes, 1993). Thus, it is possible that inhibitory and excitatory terminals compete for the same postsynaptic space. For example, when sound is located closer to the "inhibitory" ear, the MNTB terminals responding to a specific frequency are activated first, and it is these terminals that must suppress discharge in the LSO neuron. Inhibitory terminals that are activated at a longer latency, after the excitatory terminals have depolarized the LSO neuron, may be inappropriate (for example, tuned to the incorrect frequency), and these terminals should be eliminated. Therefore, it will be important to learn about the amount and timing of excitatory and inhibitory synaptic transmission in the developing LSO and the functional changes that are brought about by each.

\section{REFERENCES}

Backus KH, Deitmer JW, Friauf E (1998) Glycine-activated currents are changed by coincident membrane depolarization in developing rat auditory brainstem neurones. J Physiol (Lond) 507:783-794.

Balice-Gordon RJ, Lichtman JW (1994) Long-term synapse loss induced by focal blockade of postsynaptic receptors. Nature 372:519-524.

Battistin T, Cherubini E (1994) Developmental shift from long-term potentiation at the mossy fibre synapses in the rat hippocampus. Eur J Neurosci 6:1750-1755.

Ben-Ari Y, Cherubini E, Corradetti R, Gaiarsa JL (1989) Giant synaptic potentials in immature rat CA3 hippocampal neurones. J Physiol (Lond) 416:303-325.

Boehm S, Harvey RJ, von Holst A, Rohrer H, Betz H (1997) Glycine receptors in cultured chick sympathetic neurons are excitatory and trigger neurotransmitter release. J Physiol (Lond) 504:683-694.

Buonomano DV, Merzenich MM (1998) Net interaction between different forms of short-term synaptic plasticity and slow-IPSPs in the hippocampus and auditory cortex. J Neurophysiol 80:1765-1774.

Caicedo A, Kungel M, Pujol R, Friauf E (1998) Glutamate-induced Co ${ }^{2+}$ uptake in rat auditory brainstem neurons reveals developmental changes in $\mathrm{Ca}^{2+}$ permeability of glutamate receptors. Eur J Neurosci 10:941-954.

Callaway JC, Lasser-Ross N, Ross WN (1995) IPSPs strongly inhibit climbing fiber-activated $\left[\mathrm{Ca}^{2+}\right]_{\mathrm{i}}$ increases in the dendrites of cerebellar Purkinje neurons. J Neurosci 15:2777-2787.

Cash S, Dan Y, Poo M-m, Zucker R (1996) Postsynaptic elevation of calcium induces persistent depression of developing neuromuscular synapses. Neuron 16:745-754.

Colman H, Nabekura J, Lichtman JW (1997) Alterations in synaptic strength preceding axon withdrawal. Science 275:356-361.

Connold AL, Evers JV, Vrbova G (1986) Effect of low calcium and protease inhibitors on synapse elimination during postnatal development in the rat soleus muscle. Dev Brain Res 28:99-107.

Connor JA, Tseng HY, Hockberger PE (1987) Depolarization- and transmitter-induced changes in intracellular $\mathrm{Ca}^{2+}$ of rat cerebellar granule cells in explant cultures. J Neurosci 7:1384-1400.

Constantine-Paton M, Cline HT (1998) LTP and activity-dependent synaptogenesis: the more alike they are, the more different they become. Curr Opin Neurobiol 8:139-148.

Constantine-Paton M, Cline HT, Debski E (1990) Patterned activity, synaptic convergence, and the NMDA receptor in developing visual pathways. Annu Rev Neurosci 13:129-154.

Crair MC, Malenka RC (1995) A critical period for long-term potentiation at thalamocortical synapses. Nature 375:325-328.

Dudek SM, Bear MF (1992) Homosynaptic long-term depression in area CA1 of hippocampus and effects of $N$-methyl-D-aspartate receptor blockade. Proc Natl Acad Sci USA 89:4363-4367.

Dudek SM, Friedlander MJ (1996) Developmental down-regulation of LTD in cortical layer IV and its independence of modulation by inhibition. Neuron 16:1097-1106.

Ehrlich I, Löhrke S, Friauf E (1999) Shift from depolarizing to hyperpolarizing glycine action in rat auditory neurones is due to age-dependent $\mathrm{Cl}^{-}$regulation. J Physiol (Lond) 520:121-137.

Feldman DE, Nicoll RA, Malenka RC, Issac JT (1998) Long-term depression at thalamocortical synapses in developing rat somatosensory cortex. Neuron 21:347-357.

Finck A, Schneck CHD, Hartman AF (1972) Development of cochlear function in the neonate Mongolian gerbil (Meriones unguiculatus). J Comp Physiol Psychol 78:375-380.

Fitzgerald KK, Sanes DH (1999) Serotonergic modulation of synapses in the developing gerbil lateral superior olive. J Neurophysiol 81:2743-2752.

Friauf E (1994) Distribution of calcium-binding protein calbindin-D28k in the auditory system of adult and developing rats. J Comp Neurol 349:193-211.

Glitsch M, Llano I, Marty AJ (1996) Glutamate as a candidate retrograde messenger at interneurone-Purkinje cell synapses of rat cerebellum. J Physiol (Lond) 497:531-537.

Hafidi A (1999) Distribution of BDNF, NT-3, and NT-4 in the developing auditory brainstem. Int J Dev Neurosci 17:285-294.

Hafidi A, Moore T, Sanes DH (1996) Regional distribution of neurotrophin receptors in the developing auditory brainstem. J Comp Neurol 367:454-464.

Harris DM, Dallos P (1984) Ontogenic changes in frequency mapping of a mammalian ear. Science 225:741-743.

Henkel CK, Brunso-Bechtold JK (1998) Calcium-binding proteins and GABA reveal spatial segregation of cell types within the developing lateral superior olivary nucleus of the ferret. Microsc Res Tech 41:234-245.

Ito S, Cherubini E (1991) Strychnine-sensitive glycine responses of neonatal rat hippocampal neurones. J Physiol (Lond) 440:67-83.

Iwasaki S, Takahashi T (1998) Developmental changes in calcium channel types mediating synaptic transmission in rat auditory brainstem. J Physiol (Lond) 509:419-423.

Kakazu Y, Akaike N, Komiyama S, Nabekura J (1999) Regulation of intracellular chloride by cotransporters in developing lateral superior olive neurons. J Neurosci 19:2843-2851.

Kandler K, Friauf E (1995) Development of glycinergic and glutamatergic synaptic transmission in the auditory brainstem of perinatal rats. J Neurosci 15:6890-6904.

Kapfer C, Seidl A, Schweizer H, Koch U, Grothe B (1999) Activity dependent refinement of glycinergic input to medial superior olivary neurons in the gerbil. Assoc Res Otolaryngol Abstr 273:69.

Komatsu Y (1994) Age-dependent long-term potentiation of inhibitory synaptic transmission in rat visual cortex. J Neurosci 14:6488-6499.

Kotak VC, Sanes DH (1995) Synaptically evoked prolonged depolarizations in the developing auditory system. J Neurophysiol 74:1611-1620.

Kotak VC, Sanes DH (1996) Developmental influence of glycinergic transmission: regulation of NMDA receptor-mediated EPSPs. J Neurosci 16:1836-1843.

Kotak VC, Korada S, Schwartz IR, Sanes DH (1998) A developmental shift from GABAergic to glycinergic transmission in the central auditory system. J Neurosci 18:4646-4655.

Kullman PMH, Kandler K (1999) Glycine and GABA raise $\left[\mathrm{Ca}^{2+}\right]_{\mathrm{i}}$ in developing neurons of the lateral superior olive. Soc Neurosci Abstr 25:394.

Linden DJ, Connor JA (1995) Long-term synaptic depression. Annu Rev Neurosci 18:319-357.

Lo Y-J, Poo M-m (1994) Heterosynaptic suppression of developing neuromuscular synapses in culture. J Neurosci 14:4684-4693.

Lo Y-J, Rao SC, Sanes DH (1998) Modulation of calcium by inhibitory 
systems in the developing auditory midbrain. Neuroscience 83:1075-1084

Lohmann C, Friauf E (1996) Distribution of the calcium-binding proteins parvalbumin and calretinin in the auditory brainstem of adult and developing rats. J Comp Neurol 367:90-109.

Lu J, Karadsheh M, Delpire E (1999) Developmental regulation of the neuronal-specific isoform of the K-Cl cotransporter KCC2 in postnatal rat brains. J Neurobiol 39:558-568.

Morishita W, Sastry BR (1991) Chelation of postsynaptic $\mathrm{Ca}^{2+}$ facilitates long-term potentiation of hippocampal IPSPs. NeuroReport 2:533-536.

Morishita W, Kirov SA, Alger BE (1998) Evidence for metabotropic glutamate receptor activation in the induction of depolarization-induced depression of inhibition in hippocampal CA1. J Neurosci 18:4870-4882.

O'Brien RA, Ostberg AJ, Vrbová G (1978) Observations on the elimination of polyneuronal innervation in developing mammalian skeletal muscle. J Physiol (Lond) 282:571-582.

Obrietan K, Van den Pol AN (1995) GABA neurotransmission in the hypothalamus: developmental reversal from $\mathrm{Ca}^{2+}$ elevating to depressing. J Neurosci 15:5065-5077.

Oda Y, Charpier S, Murayama Y, Suma C, Korn H (1995) Long-term potentiation of glycinergic inhibitory synaptic transmission. J Neurophysiol 74:1056-1074.

Oda Y, Kawasaki K, Morita M, Korn H, Matsui H (1998) Inhibitory long-term potentiation underlies auditory conditioning of goldfish escape behavior. Nature 394:182-185.

Parks TN, Code RA, Taylor DA, Solum DA, Strauss KI, Jacobowitz DM, Winsky L (1997) Calretinin expression in the chick brainstem auditory nuclei develops and is maintained independently of cochlear nerve input J Comp Neurol 383:112-121.

Payne JA, Stevenson TJ, Donaldson LF (1996) Molecular characterization of a putative K-Cl cotransporter in rat brain. A neuronal-specific isoform. J Biol Chem 271:16245-16252.

Plotkin MD, Snyder EY, Hebert SC, Delpire E (1997) Expression of the $\mathrm{Na}-\mathrm{K}-2 \mathrm{Cl}$ cotransporters developmentally regulated in postnatal rat brains: a possible mechanism underlying GABA's excitatory role in immature brain. J Neurobiol 33:781-795.
Ridge RM, Betz WJ (1984) The effect of selective, chronic stimulation on motor unit size in developing rat muscle. J Neurosci 4:2614-2620.

Rivera C, Voipio J, Payne JA, Ruusuvuori E, Lahtinen H, Lamsa K, Pirvola U, Saarma M, Kaila K (1999) The $\mathrm{K}^{+} / \mathrm{Cl}^{-}$cotransporter KCC2 renders GABA hyperpolarizing during neuronal maturation. Nature 397:251-255.

Sanes DH (1993) The development of synaptic function and integration in the central auditory system. J Neurosci 13:2627-2637.

Sanes DH, Hafidi A (1996) Glycinergic transmission regulates dendrite size in organotypic culture. J Neurobiol 31:503-511.

Sanes DH, Rubel EW (1988) The ontogeny of inhibition and excitation in the gerbil lateral superior olive. J Neurosci 8:682-700.

Sanes DH, Siverls V (1991) The development and specificity of inhibitory axonal arborizations in the lateral superior olive. J Neurobiol 22:837-854.

Sanes DH, Takács C (1993) Activity-dependent refinement of inhibitory connections. Eur J Neurosci 5:570-574.

Sanes DH, Markowitz S, Bernstein J, Wardlow J (1992) The influence of inhibitory afferents on the development of postsynaptic dendritic arbors. J Comp Neurol 321:637-644.

Shatz CJ (1990) Impulse activity and the patterning of connections during CNS development. Neuron 5:745-756.

Williams JR, Sharp JW, Kumari VG, Wilson M, Payne JA (1999) The neuron-specific $\mathrm{K}-\mathrm{Cl}$ cotransporter, $\mathrm{KCC} 2$. Antibody development and initial characterization of the protein. J Biol Chem 274:12656-12664.

Woolf NK, Ryan AF (1985) Ontogeny of neural discharge patterns in the ventral cochlear nucleus of the Mongolian gerbil. Dev Brain Res 17:131-147.

Zettel ML, Frisina RD, Haider SE, O'Neill WE (1997) Age-related changes in calbindin D-28k and calretinin immunoreactivity in the inferior colliculus of $\mathrm{CBA} / \mathrm{CaJ}$ and $\mathrm{C} 57 \mathrm{Bl} / 6$ mice. J Comp Neurol 386:92-110.

Zhang LI, Tao HW, Holt CE, Harris WA, Poo M-m (1998) A critical window for cooperation and competition among developing retinotectal synapses. Nature 395:37-44. 